Research Article

\title{
A comparative assessment of emotional intelligences and happiness index among normal sighted and visually impaired students
}

\author{
Madhur Raimule*, J. S. Bhawalkar
}

Department of Community Medicine, Dr. D Y Patil Medical College, Pimpri, Pune, India

Received: 18 September 2015

Revised: 25 September 2015

Accepted: 30 September 2015

\author{
*Correspondence: \\ Dr. Madhur Raimule, \\ E-mail: madhurraimule@gmail.com
}

Copyright: ( $)$ the author(s), publisher and licensee Medip Academy. This is an open-access article distributed under the terms of the Creative Commons Attribution Non-Commercial License, which permits unrestricted non-commercial use, distribution, and reproduction in any medium, provided the original work is properly cited.

\begin{abstract}
Background: Emotional development is also strongly affected by infantile and childhood visual impairment. Visually impaired infants may not respond and smile to human faces and may be misjudged as indifferent to social contact. Emotional development is also strongly affected by infantile and childhood visual impairment. Happiness, or "subjective wellbeing", a term that is used synonymously, refers to the subjective assessment of quality of life.

Methods: A descriptive cross sectional study was conducted in a residential school for visually impaired and another residential school for normal sighted students in 1:2 proportions. Emotional intelligence of participants was calculated using Trait Emotional Intelligence Questionnaire Children Short form. The Oxford Happiness Questionnaire (OHQ) has been derived from the Oxford Happiness Inventory. OHQ comprises 29 items. The data was analysed using statistical tool available in SPSS version 20.

Results: Mean ages of visually impaired student were 12.37 where as in normal students it was 11.71. Mean emotional intelligence score for normal sighted students was 135.98 with $\mathrm{SD}=8.49$. In case of visually impaired students it was 107.93 with $\mathrm{SD}=10.25$. Mean happiness index among normal sighted students was3.98 with $\mathrm{SD}=0.675$. Among visually impaired students it was 3.03 with $\mathrm{SD}=0.471$. There was moderate, positive correlation between social quotient and emotional intelligence which is statistically significant.

Conclusions: Mean Trait-EI score was significantly lower among visually impaired student compared with normal sighted students. Happiness quotient was calculated using Oxford happiness questionnaire. Mean happiness quotient was significantly lower among visually impaired students as compared with normal sighted controls. Emotional intelligence was found to be positively correlated with the happiness quotient.
\end{abstract}

Keywords: Visual impairment, Emotional intelligence, Happiness quotient

\section{INTRODUCTION}

Health is one of those terms which people find it difficult to define, although they are confident about its meaning.

Government of India has enacted legislation i.e. "Persons with Disability Act" in 1995 to deal psychosocial problems of disabled people, which provides education, employment, creation of barrier free environment and social security to the visually impaired children. So there is hope for visually impaired to have a happy and fruitful life in the society. ${ }^{1}$ Blindness leaves a person in a state of physical, psychological and economic dependence. The aberrant mental attitudes like rejection, guilt, and aggressiveness which reflect negative attitudes towards the life are more prevalent among visually impaired adolescents.

Emotional development is also strongly affected by infantile and childhood visual impairment. Visually 
impaired infants may not respond and smile to human faces and may be misjudged as indifferent to social contact. Early intervention can help overcome this obstacle by emphasizing verbal contact and touch. Older children may be unable to judge the emotional reactions of peers and touch. This leads to a sense of isolation, an exaggerated need for pre-dictability and rigid personality. $^{2}$

Emotional intelligence (EI) is a type of social intelligence that involves monitoring, discriminating between and using emotions to guide thinking and actions. EI is related to interpersonal and communication skills, and is important in the assessment and training of medical undergraduates. ${ }^{3}$

Hossinyan and Emamipour showed that the blind people emotional intelligence is lower than ordinary pupils in these components: self-awareness, self-expression, selfactualization, independency, interpersonal relationships, problem solving, flexibility, stress tolerance, happiness, or "subjective wellbeing", a term that is used synonymously, refers to the subjective assessment of quality of life or, in other words, the way people evaluate their lives. ${ }^{4}$ These evaluations can be both cognitive and affective, and refer to life as a whole and/or to specific domains of it, such as work and social life. ${ }^{5}$

Pervez and Yaqub reported that the level of happiness of blind children was very much associated with their level of life satisfaction as a whole. ${ }^{6}$

Keeping all these fact in view we felt a need to assess the emotional development as emotional intelligence and happiness quotient.

\section{METHODS}

A descriptive cross sectional study was conducted in a residential school for visually impaired and another residential school for normal sighted students. Study population was taken as 2:1 proportion for normal sighted ad visually impaired students. Data was collected by face to face interview.

Emotional intelligence of participants was calculated using Trait Emotional Intelligence Questionnaire Children Short form. It consists of 36 items. ${ }^{7}$ TEIQueCSF measures Global Trait EI score. Items are rated on a 5 point Likert scale. A study conducted using Trait CSF tested the reliability of the questionnaire, where the results showed satisfactory internal consistency index both in the whole sample (Cronbach alfa $=.80){ }^{8}$

An improved instrument introduced by Hills and Argyle (2002), the Oxford Happiness Questionnaire (OHQ) has been derived from the Oxford Happiness Inventory, (OHI, Argyle, Martin, \& Crossland, 1989). OHQ comprises 29 items, each presented as a single statement which can be endorsed on a uniform 6 point Likert
Scale. ${ }^{9}$ The items used a Likert scale of $1=$ strongly disagree; 2 = moderately disagree; $3=$ slightly disagree; 4 $=$ slightly agree, $5=$ moderately agree, $6=$ strongly agree. There are both positive and negative items in this questionnaire. The observation that the maximum interitem correlations within the two scales, $r=0.65$ and $r=0.58$, suggests that no two items are so alike that they are measuring the same facet of happiness. ${ }^{10}$

\section{Statistical analysis}

All the information thus collected was tabulated in accordance with variables and analysed. The data was fed into MS Excel and the data was analysed using statistical tool available in Excel, and SPSS version 20. Appropriate statistical analysis was done and interpretations were drawn.

\section{RESULTS}

Table 1: Distribution of study participants.

\begin{tabular}{|lll|}
\hline & Number & Percent \\
\hline $\begin{array}{l}\text { Normal } \\
\text { sighted }\end{array}$ & 174 & 66.7 \\
\hline $\begin{array}{l}\text { Visually } \\
\text { impaired }\end{array}$ & 87 & 33.3 \\
\hline Total & 261 & 100.0 \\
\hline
\end{tabular}

All 87 students studying in residential Blind School participated in study. Students are studying from standard 1 to standard 10. 174 students from residential school for normal sighted students were taken as 1:2 proportions with respect to their studying standard (Table. No1).

Age of initiation of schooling mainly depends on the developmental milestones. In case of visual impaired children it may further delayed due to interruption of sensory functions and lack of ability to see. Mean age of visually impaired student were 12.37 where as in normal students it was 11.71. The difference between mean ages of students in both groups was not statistically significant. $(\mathrm{p}=0.081)$ (Figure 1).

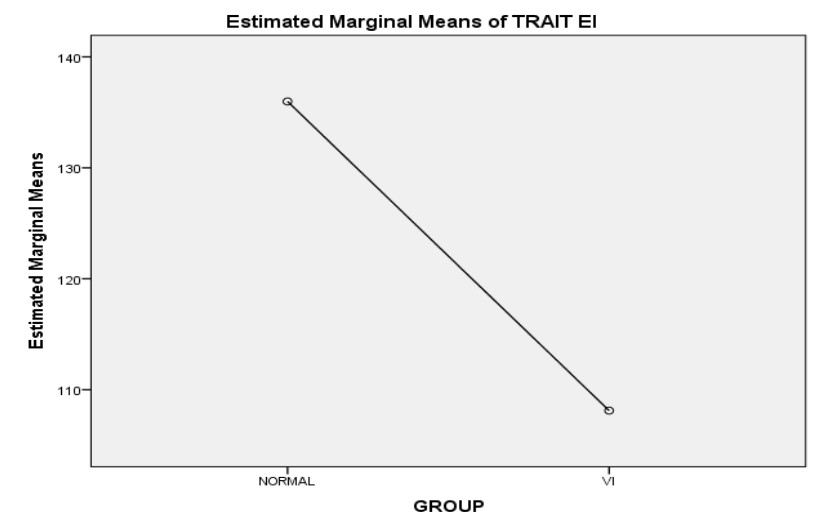

Figure 1: Mean trait EI score among normal sighted and visually impaired students. 


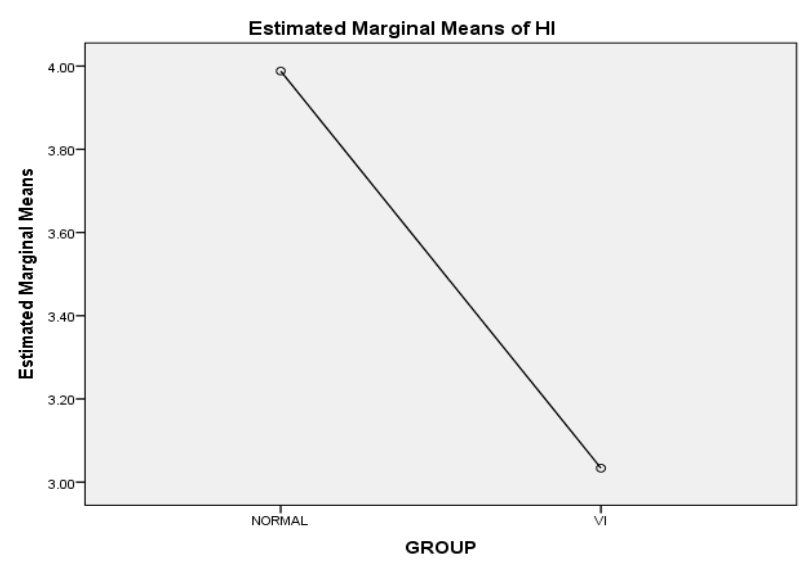

Figure 2: Mean happiness quotient among normal sighted and visually impaired students.

Mean emotional intelligence score for normal sighted students was 135.98 with $\mathrm{SD}=8.49$. In case of visually impaired students it was 107.93 with $\mathrm{SD}=10.25$. MannWhitney U Test was applied and suggest that normal sighted students have more emotional quotient as compared with visually impaired students (U=217.5, $\mathrm{P}>0.01$ ) (Figure2).

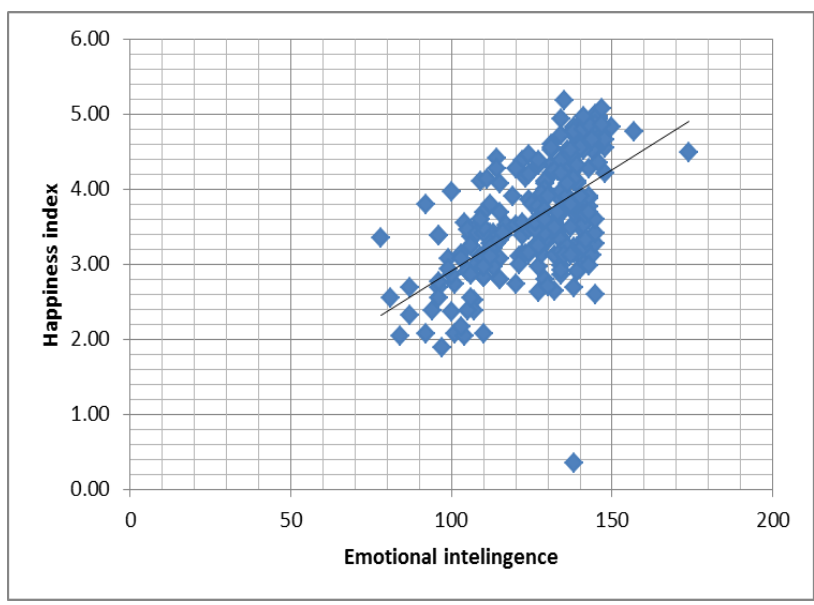

Figure 3: Correlation between trait EI and happiness index.

Mean happiness index among normal sighted students was3.98 with $\mathrm{SD}=0.675$. Among visually impaired students it was 3.03 with $\mathrm{SD}=0.471$. Mann-Whitney $\mathrm{U}$ Test was conducted and it was found Normal sighted students were happier than that of visually impaired students $(\mathrm{U}=2220.5, \mathrm{p}<0.01)$ (Figure 3$)$.

A Spearman's rank-order correlation was run to determine the relationship between emotional intelligence and happiness index. There was moderate, positive correlation between social quotient and emotional intelligence which is statistically significant. $(\mathrm{r}(\mathrm{s})=0.582$, $\mathrm{p}<0.01$ ) at 0.01 level of significance (Figure 4).

\section{DISCUSSION}

Visual impairment is an important cause of developmental disability among children, if the visual impairment is undetected or untreated it can have substantial long-term implications for the quality of the life of the child and the family and also can place the burden on public health resources. ${ }^{11}$

The present study was undertaken to have comparative assessment of emotional intelligence and happiness quotient among visually impaired and normal sighted students.

In our study we found that mean age at the time admission to the school was higher among visually impaired students as compared with normal sighted students. A study conducted by Kulkarni R and Baliga S visually impaired students in Belgaum among shows similar mean age among visually impaired students. ${ }^{12}$ Higher mean age at the time of admission may be due to delayed development milestones and perceptions.

Trait emotional intelligence scale foe children short from was used to assess emotional intelligence of the students. Mean Trait-EI score was significantly lower among visually impaired student compared with normal sighted students. The difference between both groups was statistically significant. Our results were in contradicted with the results of study conducted by Dehghan $M$ and Nazari M, that there is no emotional quotient difference among visually impaired and normal sighted students. ${ }^{13}$

A study conducted by Sushil et al supports our results that the visually impaired and sighted school student differs significantly on their emotional intelligence. Further, Sighted students were emotionally more intelligent than visually impaired students. ${ }^{14}$

Happiness quotient was calculated using Oxford happiness questionnaire. Mean happiness quotient was significantly lower among visually impaired students as compared with normal sighted controls.

Emotional intelligence was found to be positively correlated with the happiness quotient. Higher the emotional intelligence, person can efficiently control the emotions and tend to be happier. So we can conclude that, the specific direct or indirect effects of trait Emotional Intelligence on happiness were significant in both study groups. This is in agreement with previous findings reporting the effect of trait emotional intelligence on happiness. ${ }^{15-17}$

A study conducted by the Khosala M and Dokania V to assess the effect of emotional intelligence conclude that happy participants will show higher emotional intelligence than unhappy participants. ${ }^{18}$ 
Along with educational development, psycho social factors can play key role in overall development of visually impaired students. The practical implementation of the results obtained, as they suggest importance of carrying out interventions with visually impaired students aimed at improvement of emotional intelligence resulting in improved happiness quotient with the help of prospective examinations. Finally the school should not serve to produce submissive individuals or just provide concrete knowledge, but its function should be to favour the social and psychological development of the child, contributing towards the formation of free and autonomous adults in society.

\section{ACKNOWLEDGEMENTS}

We would like to thank all students and staff of both schools for their support during this study and their dedicated work for the betterment of students.

\section{Funding: No funding sources}

Conflict of interest: None declared

Ethical approval: The study was approved by the Institutional Ethics Committee

\section{REFERENCES}

1. Hadad MA, Sei M, Sampaio MW, Kara JN. Causes of visually impairment in children. $\mathrm{J}$ pediatr opthalmol strabismus. 2007;44(4):232-40.

2. Walker A, Kaufman D. Child and adolescent neurology for psychiatrists, Chapter 16. Development and neuropsychology of visual impairment: Lippincott Williams \& Wilkins. P: 3412.

3. Cherry MG, Fletcher I, O'Sullivan H, Shaw N. What impact do structured educational sessions to increase emotional intelligence have on medical students? BEME Guide No. 17. Med Teach. 2012;34:11-9.

4. Hossinyan S, Emamipour S. Comparison of emotional intelligence and assertiveness in normal and blind girls' and boys'. Journal of Applied Psychology. 2006;1:19-29.

5. Diener E, Suh E, Lucas R, Smith H. Subjective well-being: three decades of progress. Psychological Bulletin. 1999;125(2):276-302.

6. Platsidou M. Trait emotional intelligence predicts happiness, but how? An empirical study in adolescents and young adults. International Journal of Wellbeing. 2013;3(2):197-209.

7. Mavroveli S, Petrides KV, Shove C, Whitehead A. Investigation of the construct of trait emotional intelligence in children. European Child and Adolescent Psychiatry. 2008;17(8):516-26.
8. Babalis T, et al. The Impact of Social and Emotional Learning Programs on the Emotional Competence and Academic Achievement of Children in Greek Primary School. World Journal of Education. 2013;3(6):54-63.

9. Hills P, Argyle M. The Oxford Happiness Questionnaire: a compact scale for the measurement of psychological well-being. Personality and Individual Differences 33 (2002) 1073-108233 (2002) 1073-82.

10. Robins M, Fransis LJ. Happiness as stable extraversion: internal consistency reliabity and construct validity of Oxford Happiness Questioniare among undergraduate students. Current psychology. 2010;29:899-94.

11. Centers for Disease Control and Prevention. Visual Impairment and Use of Eye Care Services and Protective Eye Wear among Children 2002. MMWR Morb mortal Wkly Rep. 2005;654(17):4259.

12. Kulkarni R, Baliga S. Morbidities among blind school children in Belgaum; Int J Med Pharm Sci. 2013;03(05):11-3

13. Dehghan M, Nazari M. The comparison of Emotional Quotient in blinds and low visions with normal sighted people in Shahroud welfare organization: Iranian Journal of Rehabilitation Research in Nursing.

14. Sushil K, Singh J. Emotional intelligence and adjustment among visually impaired and sighted school students. Asian Journal of Multidimensional Research. 2013;2(8):1-8.

15. Furnham A, Petrides KV. Trait emotional intelligence and happiness. Social Behavior and Personality: An International Journal. 2003;31(8):815-23.

16. Gallagher EN, Vella-Brodrick D. Social support and emotional intelligence as predictors of subjective well-being. Personality and Individual Differences. 2008;44(7):1551-61.

17. Kong F, Zhao J, You X. Emotional intelligence and life satisfaction in Chinese university students: The mediating role of self-esteem and social support. Personality and Individual Differences. 2012;53(8):1039-43.

18. Khosla M, dokania V. Does Happiness Promote Emotional Intelligence? Journal of the Indian Academy of Applied Psychology. 2010;36(1):45-54.

Cite this article as: Raimule M, Bhawalkar JS. A comparative assessment of emotional intelligences and happiness index among normal sighted and visually impaired students. Int J Community Med Public Health 2015;2:431-4. 